Fuel Sciences Division,

S. K. Chakrabartty

N. BERKOWITZ

Alberta Research Council,

Edmonton, Alberta, Canada

1 Hayatsu, R. Scott, R., G., Moore, L. P., and Studier, M. H., Nature, 257, 378 (1975).

Chakrabartty, S., and Berkowitz, N., Fuel, 53.

3 Juettner, B., Smith, R. C., and Howard, H. C., J. Am. chem. Soc., 59, 236 (1937).

Smith, R. C., Tomarelli, R. C., nd Howard, H. C. J. Am. chem. Soc., 61, 2398(1939).

5 Kent, C. R., Fuel, 19, $119(1940)$.

Hayatsu ET AL. REPLY-First, with respect to the ease of oxidation of coal by air at $70^{\circ} \mathrm{C}$ we need only quote from ref. 1: "For example, at $180{ }^{\circ} \mathrm{C}$ and oxygen concentrations $<20 \%$, conversion to humic acids is negligible, and significant reaction rates at this temperature are only observed when [O] $>50 \%$ ".

Detailed pyrolysis studies of the bituminous coal we used for our experiments showed no evidence of thermal decomposition until the coal was heated well above $250^{\circ} \mathrm{C}$.

Second, the estimate of the degree of aromatic structure from our data is much too low for the following reasons: (a) Because of the large concentrations of salts resulting from oxidation with $\mathrm{Na}_{2} \mathrm{Cr}_{2} \mathrm{O}_{7}$, yields were not quantitative and were estimated to be $\sim 75 \%$. As we mentioned in our paper the amphoteric acids were not isolated from this oxidation but were identified in the product from a photochemical oxidation with much less interfering residues; (b) a significant fraction of the aromatic compounds appeared in a neutral fraction, and (c) as Friedman has shown, aromatic rings containing phenolic groups would have been destroyed by $\mathrm{Na}_{2} \mathrm{Cr}_{2} \mathrm{O}_{7}$.

By a method based on the stoichiometry of fluorination reactions ( $\mathrm{J}$. Huston, R. G. Scott, and M. H. Studier, unpublished) we have calculated the aromaticity to be $69 \%$.

Third, we agree that the strength of an oxidising agent is less important than its specificity in studying coal structure. Friedman ${ }^{2}$ has demonstrated the selectivity of aqueous sodium dichromate in an autoclave at $250{ }^{\circ} \mathrm{C}$ without pyrolytic cleavage or structural rearrangements occurring. Several authors ${ }^{3-5}$ have shown the nonspecificity of aqueous $\mathrm{NaOCl}$, the reactions of which are the basis of Chakrabartty's and Berkowitz's postulate that coal is primarily non-aromatic.

We feel it more likely that coal consists of aromatic units bridged largely by aliphatic and hydro-aromatic groups than that it has a 'diamondoid' structure.

Chemistry Division,

Argonne National Laboratory, Illinois 60439

2 Jensen, E. J., Melnyk, N., Wood, J. C., and Berkowitz, N., Adv. Chem. Ser., 55, 621 (American Chemical Society (1966).
2 Friedman, L., Fishel, L., and Shechter, H., J. org. Chem., 30,1453 (1965).

3 Mayo, F. R., Fuel, 54, 274 (1975).

Ghosh, G., Banerjee, A., and Mazumdar, B. K. Fuel, 54, 294 (1975).

5 Landolt, R.G., Fuel, 54, 299 (1975).

\section{Trapped helium and argon and}

\section{formation of the atmosphere}

FISHER ${ }^{1}$ reports ${ }^{4} \mathrm{He} /{ }^{40} \mathrm{Ar}$ ratios from analyses of the glassy margins of several deep sea basalts which are higher than can be generated by the in situ decay of $\mathrm{K}, \mathrm{U}$ and $\mathrm{Th}$ in the mantle if one uses conventional estimates for the $\mathrm{K} / \mathrm{U}$ and $\mathrm{Th} / \mathrm{U}$ ratios in the mantle. $\mathrm{He}$ then concludes that "the data rule out all models which ascribe the terrestrial atmosphere to any type of degassing of a mantle which is chondritic or crustal with respect to the K/U ratio". While this sweeping conclusion may ultimately prove correct, Fisher's argument is suspect since it involves an assumption which is probably false. The assumption is explicitly stated: "The rare gases found in deep sea basaltic glasses are clearly those trapped within the rock on its eruption, due to the high hydrostatic pressures and rapid chilling, and as such represent mantle-ambient gases".

Oceanic basalt magmas are commonly taken to be fractionated (by partial melting) samples of the mantle. Ozima and Alexander (unpublished) have argued that the partial melting process produces large enrichments of light rare gases relative to the heavy rare gases in the melt phase. For example, Gramlich and Naughton ${ }^{2}$ have shown that Iherzolite nodules, which they conclude represent unfused residue from the partial melting process, contain ${ }^{4} \mathrm{He} /{ }^{40} \mathrm{Ar}$ ratios lower than reasonable values. If the residue is depleted in ${ }^{4} \mathrm{He}$ relative to ${ }^{10} \mathrm{Ar}$, simple mass balance requires that the melt phase be enriched in " $\mathrm{He}$ relative to ${ }^{40} \mathrm{Ar}$. While data from the glassy rims do probably represent lower limits on the ${ }^{4} \mathrm{He} /{ }^{40} \mathrm{Ar}$ ratios in the magma, the magma values are only bad upper limits on the mantle-ambient values. The magma ${ }^{4} \mathrm{He} /{ }^{40} \mathrm{Ar}$ ratios do not, therefore, rule out the degassing models mentioned above.

E. Calvin Alexander, JR

Department of Geology and

Geophysics,

University of Minnesota,

Minneapolis, Minnesota 55455

1 Fisher, D. E., Nature, 256, $113-114$ (1975)

Gramlich, J. W., and Naughton, J. J., J. geophys.

Fisher REPLIES-The suggestion of Alexander ${ }^{1}$ (based on unpublished work of Ozima and Alexander) that the ${ }^{4} \mathrm{He} /{ }^{40} \mathrm{Ar}$ ratio may be quantitatively enriched in the mantle-magma segregation process is certainly interesting, though unproven. Alexander's sugges- tion that Gramlich and Naughton ${ }^{2}$ concluded that their samples represent residue from the partial melting process with $\mathrm{He}$ depleted relative to $\mathrm{Ar}$, and therefore that the melt phase must be enriched in $\mathrm{He}$ relative to $\mathrm{Ar}$, ignores Gramlich and Naughton's actual interpretation of their data: that their gas ratios were probably "altered during a high temperature episode such as that existing during transport in the erupting lava"2.

We know that such a high temperature episode existed (the eruption itself), and that this would segregate $\mathrm{He}$ from Ar; therefore we cannot use these data as evidence for another and previous segregation process, as Alexander would like. The simplest interpretation of my data remains that the measured ratios represent those in the source material except as modified during eruption; that is, they are lower limits to the mantle-ambient ratios. Experimental investigations that might prove the reality of the OzimaAlexander model will be welcomed.

Alexander (personal communication) has pointed out an error in Fig. 1 of my paper $^{3}$ : the values for all curves below $10^{7}$ yr should be levelling off, not decreasing. This does not affect in any way the arguments presented either there or here.

Rosenstiel School of Marine and

Atmospheric Science,

University of Miami,

Miami, Florida, 33149

1 Alexander, E. C., Jr., Nature, 261, 77 (1976). 2 Gramlich, J. W., and Naughton, J. J., J. geophys.

Res., 77, 3032-3042 (1972).
${ }^{3}$ Fisher, D. E., Nature, 256, 113-114 (1975).

\section{Ambiguous cognitive contours}

BRADLEY and Dumais ${ }^{1}$ have presented figures that induce ambiguous subjective contours, which tend to alternate between two (or more) perceived forms. Bradlev and Dumais suggested that bacause these figures are not "stimulus-bound", they cannot be accounted for by a physiological model, but arise when alternative perceptual hypotheses are tested ${ }^{2}$. Although this account is plausible, a more physiological explanation may also exist. The alternation of perceived forms resembles an effect described by Campbell et $a l^{3,4}$ : if two gratings that have sinusoidal luminance profiles are projected so that their axes are at an angle to one another, the gratings tend to be seen in alternation, one replacing the other at intervals of several seconds. Campbell et al. suggest that this occurs because while one grating is perceived, the channel that is most sensitive to that grating becomes adapted. When adapted, its sensitivity decreases ${ }^{5}$, allowing the other grating to predominate.

When observed steadily, Bradley and Dumais' patterns undergo a similar 